\title{
The nature and determinants of spatial retreat in the pigeon between periodic grain presentations
}

\author{
PERRIN S. COHEN and F. R. CAMPAGNONI \\ Northeastern University, Boston, Massachusetts
}

\begin{abstract}
Pigeons were exposed to fixed-time and fixed-interval schedules that ranged from 30 to 960 sec. The probability of a subject's location in the rear of the chamber (away from the reinforcer dispenser) peaked during the postreinforcer period, and was referenced to proportional time between reinforcers. Increasing the interreinforcer interval generally increased time in the rear. In some sessions (Experiment 1), location in the rear produced an explicit stimulus change (altered the color and intensity of lights, i.e., time-out); this change increased time spent in the rear without affecting its temporal locus or its relation to the interreinforcer interval. During Experiment 2, a keypeck (near the reinforcer site) produced the explicit stimulus change used in Experiment 1. The characteristics of keypeck time-out resembled those of movement to the rear of the chamber (with and without an explicit stimulus change), suggesting that movement away from the reinforcer site is functionally homologous to keypeck time-out.
\end{abstract}

Periodic presentation of a reinforcing event causes subjects' behavior to become organized around the reward deliveries in a distinctive manner. As reward delivery becomes imminent, subjects engage predominantly in behaviors directed toward acquisition of the scheduled reinforcer. In the period following reward presentation, when additional reward is unavailable, subjects typically turn or move away from the reinforcer dispenser and engage in activities directed toward other parts of the experimental environment (Staddon \& Simmelhag, 1971). It has been suggested that this retreat from the area where reward occurs is maintained, in part, by the change in visual stimulation consequent to such behavior (Falk, 1977; Rand, 1977). This view is consistent with the fact that subjects that receive periodic reward will perform an operant response for contingent stimulus change during the period following reward delivery (time-out responding; Brown \& Flory, 1972; Lydersen, Perkins, Thome, \& Lowman, 1980). In the present study, we investigated pigeons' spatial retreat from the reinforcer site following periodic grain presentations and examined its relation to operant time-out responding for stimulus change. ("Timeout" and "responding for stimulus change" are used interchangeably in this paper.)

\section{EXPERIMENT 1}

Preliminary observations in our laboratory indicated that during exposure to periodic food reinforcement, hungry

This research was supported in part by USPHS Grant RR07413 to Northeastern University. The authors thank Cindy Lawler for her comments on an earlier draft of this paper. Requests for reprints should be sent to Perrin S. Cohen, Psychology Department, Northeastern University, 360 Huntington Avenue, Boston, MA 02115. pigeons spend more time away from the reinforcer dispenser during the postreinforcer period if stimulus change is contingent upon their being away from the reinforcer dispenser than if it is not. This enhanced level of spatial retreat occurred with little change in its momentary probability of occurrence within the interreinforcer interval. These preliminary observations suggested that the causal factors that control the temporal locus of spatial retreat remain unchanged (McFarland, 1969) when retreat is enhanced by additional visual feedback. They also suggested that spatial retreat normally is maintained, in part, by the intrinsic change in visual feedback that accompanies it. The purpose of Experiment 1 was to further explore and expand these preliminary observations as a basis for relating spatial retreat to time-out responding for stimulus change. Specifically, Experiment 1 examined the overall level and momentary probability of spatial retreat under conditions in which additional visual feedback for spatial retreat sometimes occurred. This was done for a range of interreinforcer interval values.

Previous parametric time-out studies in which a keypeck or barpress produced stimulus change found that the proportion of session time spent in the time-out condition is generally an increasing function of increasing the interreinforcer interval over a wide range of interval values (Falk, 1981; Lydersen et al., 1980), although there is some evidence (e.g., Brown \& Flory, 1972) that it decreases at very long intervals. This increasing function has been viewed as reflecting an increasing aversiveness of the schedule as the interval is increased (Azrin, 1961; Falk, 1981). Brown and Flory (1972) accounted for the decreasing limb of the function at the longest intervals in terms of the decreasing rate of transitions from reinforcement to nonreinforcement. 
If, as we hypothesize, retreat from the reinforcer site is functionally homologous to keypeck time-out, then proportion of time spent in the rear of the chamber in this experiment and keypeck time-out should be similarly influenced by changes in the interreinforcer interval. This should be true regardless of whether or not location in the rear is accompanied by explicit stimulus change.

Experiment 1 also afforded an opportunity to examine more closely the momentary probability of spatial retreat over a range of interval values. Comparatively little attention has focused on the distribution of time-out behavior within the interreinforcer interval (Ator, 1980). Most reports have utilized fairly crude measures to depict temporal distribution, measures such as time-out initiations in quarters of the interval.

In Experiment 1, subjects were exposed to either response-independent (fixed-time, or FT) or responsedependent (fixed-interval, or FI) periodic schedules of grain presentation, both of which are known to maintain subject-initiated stimulus change (Brown \& Flory, 1972; Lydersen et al., 1977). The two-group design was used to assess whether an explicitly conditioned operant response competes with time-out responding, affecting its level and temporal pattern.

\section{Method}

Subjects. Six male, White King pigeons were maintained at $80 \%$ $( \pm 20 \mathrm{~g}$ ) of their ad-lib weights. Birds were housed in individual cages under a light:dark cycle (lights on from 0700 to 2300) and had free access to water and health grit in the home cage. Two pigeons that were in the FT group (P8556 and P9409) had a history of exposure to a fixed-time 90 -sec schedule (Yoburn, Cohen, \& Campagnoni, 1981, Experiment 2) and were used in the pilot study mentioned above. The subjects in the FI group were 4 experimentally naive pigeons (P3440, P511, P6933, and P3421).

Apparatus. Testing was conducted in a standard, black operant chamber $(33 \times 36 \times 35 \mathrm{~cm})$ contained inside a $63 \times 109 \times 102 \mathrm{~cm}$ dark enclosure. The chamber was equipped with a grain dispenser with a light centered on one wall. A translucent pecking key was centered above the dispenser opening and could be illuminated with red or green light. Six $2-W$, roof-mounted lights illuminated the chamber from behind a sheet of opaque Plexiglas. The houselights were arranged in two parallel rows of three bulbs, perpendicular to the wall containing the grain dispenser. A white-noise generator and exhaust fan masked extraneous noise.

The subjects' location was monitored by an infrared photodetection system that allowed separate measurement of time spent near the grain dispenser (interruption of photobeam located approximately $8 \mathrm{~cm}$ from the front wall), time spent near the rear wall opposite the dispenser (interruption of photobeam located approximately $8 \mathrm{~cm}$ from the rear wall), and time spent between those areas. The subjects' spatial position during the interreinforcer interval was sampled 60 times per minute, and the data were cumulated into each of 15 equal time bins that varied from 2 to $64 \mathrm{sec}$ in width, depending on the interval length. For the fixed-interval subjects, pecks to the response key were accompanied by audible clicks and were distributed to one of 15 counters as a function of time since the last food delivery. Pecks at the response key were not paired with the click for the fixed-time animals since the response key was ineffective for those subjects. Experimental conditions were controlled and data were recorded by standard electromechanical equipment located in an adjacent room.

Procedure. Subjects in the FT group were exposed to an ascending and descending series of interreinforcer intervals in the following order: $30,60,120,240,480,960,240,120,60$, and $30 \mathrm{sec}$. At the end of each specified interval value, subjects were allowed $7 \mathrm{sec}$ access to grain independent of their behavior. Each session consisted of 16 reinforcer deliveries, except at the 960 -sec interval where sessions were terminated after 8 reinforcer presentations. Each session began and ended with a reward delivery. The subjects were exposed to 30 sessions at each interval value except at the 960 -sec interval. Since sessions at the 960 -sec interval were terminated after 8 reinforcer deliveries, twice as many sessions were run at that condition to ensure that the total number of reward deliveries was constant across interval values. During the first 15 sessions ( 30 for the 960 -sec interval), location in the rear did not produce a change in stimulus conditions. During the final 15 (or 30) sessions, interruption of the rear photobeam initiated an explicit change in stimulus conditions. During this time-out period, six houselights rather than one were illuminated, and the color of the keylight changed from green to red for the duration of the time that the rear photobeam was interrupted. Thus subjects could both initiate and terminate the change in stimuli by moving to or away from the rear of the chamber. During stimulus change, the timer controlling the interval between reward deliveries continued to operate. No effort was made to prevent temporal contiguity between interruption of the rear photobeam and reinforcer delivery since birds are infrequently in the rear during the $5-10 \mathrm{sec}$ immediately preceding reinforcer delivery (Yoburn et al., 1981). Also, such a protective contingency (Herrnstein, 1961) could affect the amount and momentary probability of time spent in the rear of the chamber.

Subjects in the FI group were exposed to interreinforcer intervals in the following order: $30,60,120,240,480,960,120,60$, and $30 \mathrm{sec}$. The first keypeck to occur after the specified interval length was followed by $7 \mathrm{sec}$ access to grain. As for the FT subjects, each session consisted of 16 reinforcer deliveries, except at the 960 -sec interval, where sessions were terminated after 8 reinforcer presentations. Each session ended with a reward delivery. These subjects were exposed to the entire series ( 15 or 30 sessions per interval value) without an explicit stimulus change contingency and were then reexposed to the same series of interval values with the stimulus change contingency in effect.

Unless otherwise indicated, data presented for this experiment are based on the last 5 sessions at each interval value and condition except for the $960-\mathrm{sec}$ interval, where the data were based on the last 10 sessions.

\section{Results}

The effect of contingent stimulus change on time spent in the rear. Figure 1 depicts, for FT subjects (upper panel) and FI subjects (lower panel), the probability of retreat to the rear when accompanied or unaccompanied by stimulus change at each interval value (ascending series). Probability was calculated by dividing the total number of samples with rear photobeam interruption by the total samples in a session. In general, interruption of the rear photobeam was more likely to occur if it was accompanied by stimulus change than if it was not. Subject P511 was least consistent in this respect. A significant difference was not shown by Subject P9409 at the 30- and 960-sec intervals (dependent $t, p>.05$ ) or by Subject P8556 at the 480-sec interval (dependent $t, p>.05$ ). Overall levels of time in the rear were similar for subjects in the FT and FI groups.

In general, the subjects showed small session-by-session variability in probability of location in the rear both within and across interval values. In addition, introduction of the stimulus change contingency enhanced the level but not 


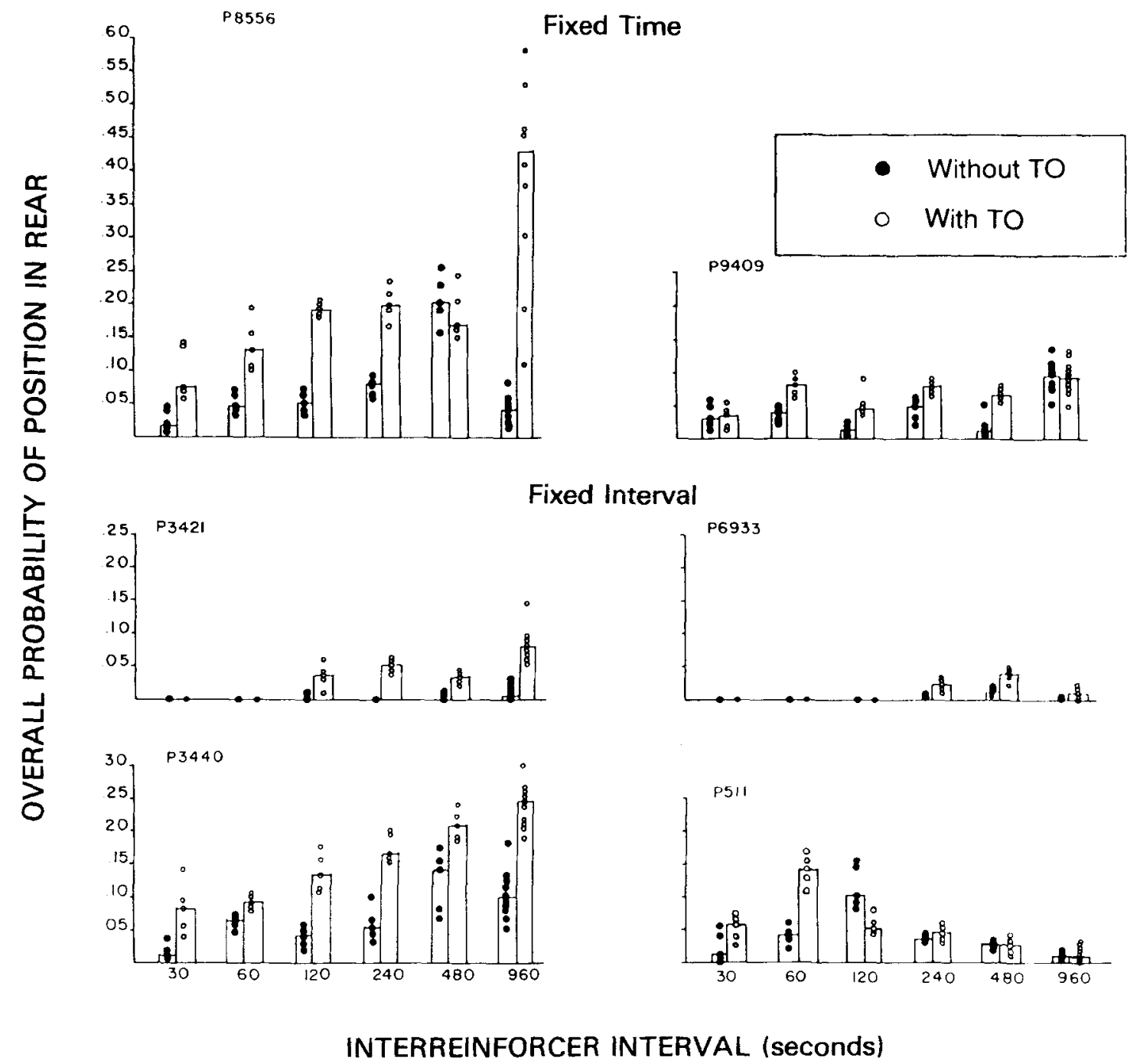

Figure 1. Proportion of total session time spent in the rear for the last 5 sessions in each interval value in ascending series. The last 10 sessions are plotted at the $960-\mathbf{s e c}$ interval. The histograms enclose median values.

the variability of the behavior. Data obtained on the descending series, which are not shown, were consistent with those shown in Figure 1, although the absolute levels of time spent in the rear were sometimes different (see Figures 2 and 3 ).

The effect of the interreinforcer interval on the probability of location in the rear. Figures 2 and 3 show the proportion of total session in the rear for all 6 subjects at each interval value for both the ascending and descending series. With few exceptions, the functions for each subject were similar across interreinforcer interval values, regardless of whether or not location in the rear was accompanied by stimulus change. There were differences between subjects in terms of the effect of interreinforcer interval on the proportion of total time spent in the rear.

For 4 of the 6 subjects (P8556 exposed to the FT schedules; P3440, P6933, and P3421 exposed to the FI sched- ules), overall probability of location in the rear was generally an increasing function of the interreinforcer interval both with and without explicit stimulus change. As previously reported by Brown and Flory (1972) for time-out responding, there was a tendency, in some cases, for the probability to level off or decrease at the 480- and 960$\mathrm{sec}$ intervals. The general trends of the functions shown by these 4 subjects were essentially replicated on the descending series. Overall, these data are consistent with the report by Lydersen et al. (1980) and with suggestions by Falk (1981) that the tendency to leave the reinforcer site is an increasing function of the interval width over a wide range of values. There is some support for Brown and Flory's (1972) finding of a bitonic function. However, the question of how to interpret the descending limb is problematic. As we discuss below, the spatial patterning of behavior breaks down somewhat at longer interval 

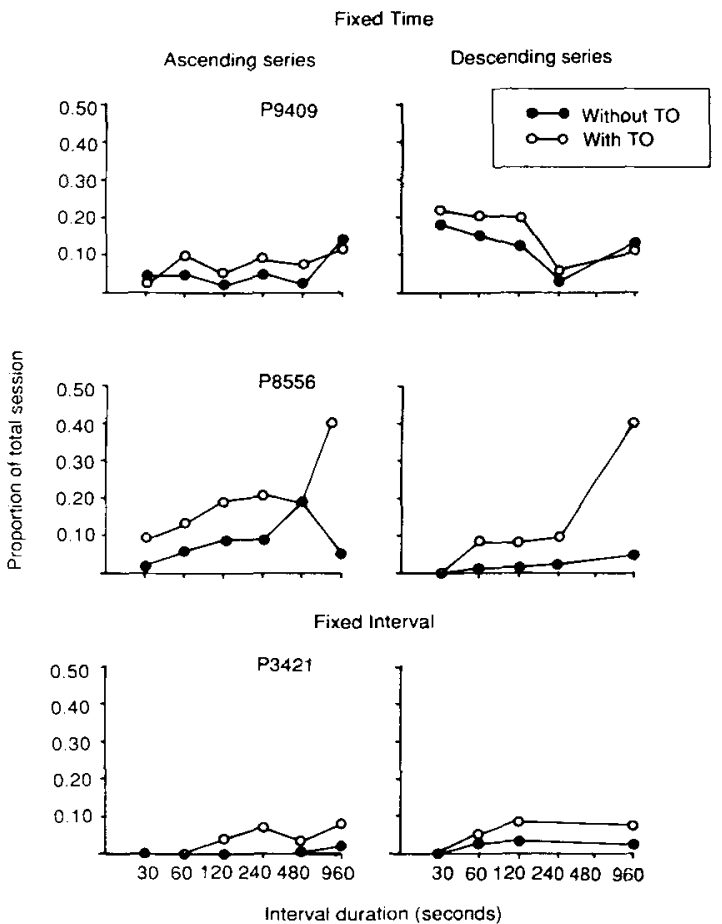

Figure 2. Fixed-time and fixed-interval subjects' mean overall probability of location in the rear as a function of interreinforcer interval length for the ascending and descending series.

values, and the scheduled reward may exert less control over probability of location in the rear in these instances (Zimmerman \& Ferster, 1964). For the remaining two subjects (P9409 and P511), the effect of changes in the interreinforcer interval on time spent in the rear was different in the ascending and descending series and is thus more difficult to interpret.

The effect of interreinforcer interval on allocation of time spent in the rear between reinforcer deliveries. Figures 4 and 5 show how the relative probability of location in the rear varied between reward deliveries in the ascending series. The data for the descending series were similar and are not presented. Probability was calculated by dividing number of samples in which the rear photobeam was broken by total number of sampled opportunities. These normalized (Dews, 1970; Gibbon, 1977) functions are independent of the total amount of time spent in the rear and are unreliable when a low level of behavior occurs. For this latter reason, functions are not included for P6933 (in either condition) or for P3421 (condition without stimulus change).

Figures 4 and 5 present the data obtained when location in the rear was unaccompanied and accompanied by stimulus change, respectively. Under both conditions and across most interval values, subjects were most likely to be in the rear of the chamber after $15 \%-25 \%$ of the interval between reward deliveries had elapsed. Although tending to flatten somewhat at higher interval values, the functions, both within and between animals, tend to superimpose on one another over a wide range of intervals. Thus, the probability of location in the rear, like operant behavior and general activity (Gibbon, 1977), appears to be distributed proportionally within the interval between rewards rather than to follow a fixed temporal pattern. In other words, the temporal pattern of spatial retreat is generally sensitive to the time between reinforcer presentations. P511, however, is a particularly poor example of such proportional timing when location in the rear both was and was not accompanied by stimulus change. For this subject, time in the rear occurred at approximately the same time after reinforcer termination regardless of the interreinforcer interval. As a result, the functions in Figures $\mathbf{4}$ and 5 for this subject shift increasingly toward grain termination as the interreinforcer interval is increased.

As is apparent in Figures 4 and 5, there is a slight but systematic tendency for the other probability functions also to shift toward grain termination as the interreinforcer interval is increased. This shift may reflect, in part, postreinforcer consummatory behaviors (e.g., head in the food dispenser) whose time courses are unaffected by the interval between reward deliveries. As a result, time spent engaging in these behaviors constitutes a greater portion of the interreinforcer interval at shorter intervals, and therefore constrains the onset of movement away from the dispenser relatively more at lower interval values.
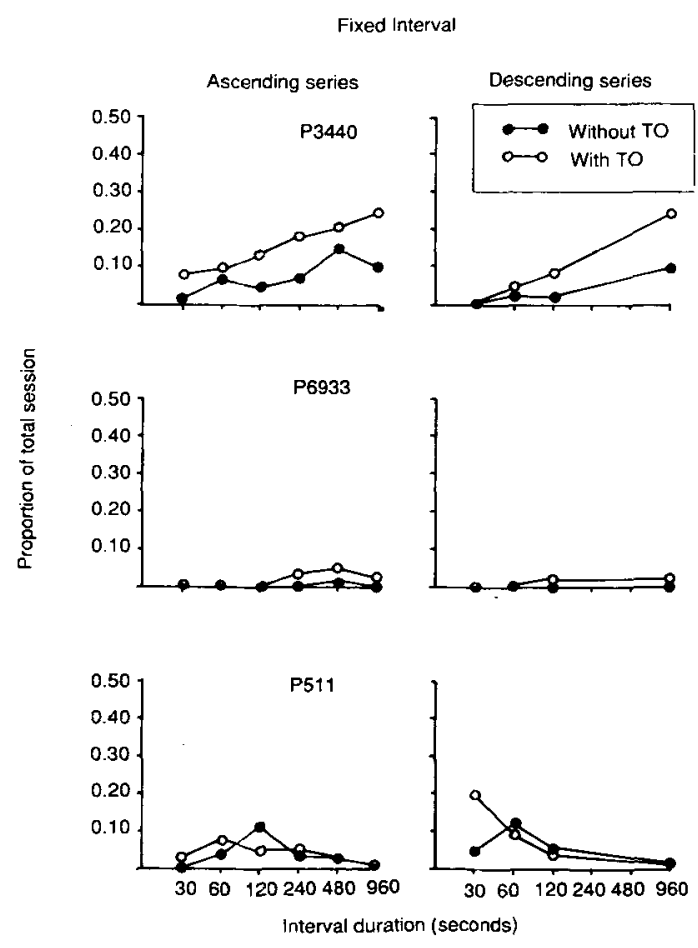

Figure 3. Fixed-interval subjects' mean overall probability of location in the rear as a function of interreinforcer interval length for ascending and descending series. 


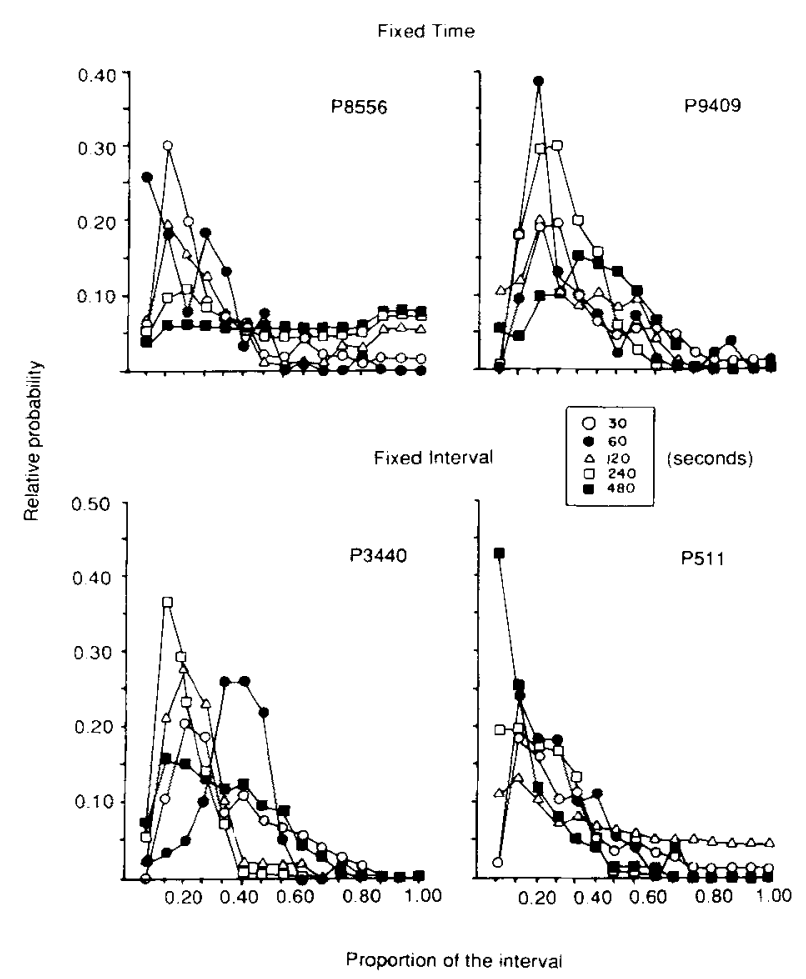

Figure 4. Relative probability of location in the rear as a function of time in the interval for the ascending series without contingent stimulus change.

Another possibility is that the timing mechanism is not completely proportional and the interval is underestimated at the longer values (Dews, 1970).

The probability functions show more similarity to each other when location in the rear was accompanied by stimulus change than when it was not. This may be because the abrupt change in chamber illumination and keylight color gave explicit feedback to the subject of its spatial location. Without explicit stimulus change, movement to the rear is less discriminable from other locations.

At the 960 -sec interval value (not shown), distributions of time spent in the rear became more evenly dispersed in the interval. It appears that at longer interval values, intermittent reward exerts a weaker influence on the spatial differentiation of behavior than at the shorter intervals. This is not due to the longer intervals' exerting less control over all behavior since operant keypecking in the FI group was maintained at comparable rates at long and short interval values (Brown \& Flory, 1972).

The effect of operant response on level and momentary probability of time spent in the rear. The operant response necessary to produce grain for the FI group did not exert a major influence on the amount of time spent in the rear of the chamber or on its temporal distribution. Total time spent in the rear for the FI group was marginally lower, but the statistical comparisons are not significant $(t$ test, $p>.05$ ).

\section{Discussion}

As in our preliminary study, pigeons in this experiment generally spent more time in the rear of the chamber when visual stimulation was contingent upon interruption of the rear photobeam. In both stimulus-change and no-stimuluschange conditions, time spent in the rear was similarly affected by changes in the interreinforcer interval.

As was also evident in our preliminary study, providing additional visual feedback for interrupting the rear photobeam increased time spent in that location without significantly affecting the momentary probability of spatial retreat within the interreinforcer interval. Furthermore, in this experiment the temporal distributions of time spent in the rear were consistent across subjects and showed that subjects generally allocated time in that location according to proportion of the interreinforcer interval rather than with respect to absolute time. Proportional timing was most apparent when location in the rear produced stimulus change, probably because this change provided a greater degree of feedback to the subject regarding its position in the chamber. Thus the momentary probability of spatial retreat was sharper and more consistent.

The proportional nature of the distributions of time spent in the rear is consistent with scalar expectancy theory (Gibbon, 1977) of animal timing. Scalar expectancy theory presumes that behavior is directly related to the subject's estimate of the time until reinforcer presentation. It is a discrimination model of temporal control in which the degree of discriminability of time is related to the magnitude of the interval being estimated (Weber's law).

From this perspective, the temporal locus of interim states (Staddon, 1977) is controlled by the expectancy of reward. Due to the scalar nature of the estimation process, the peak levels of an interim behavior, such as general activity, should, and in fact do (Campagnoni, Lawler, \& Cohen, 1986; Gibbon, 1977), occur at about the same proportional point in an interval regardless of the absolute interval duration. If time spent away from the food dispenser was controlled by a similar temporal discrimination process in the present study, then scalar expectancy theory predicts that location in the rear should be proportionally distributed between reinforcers. This prediction was generally confirmed, although a slight systematic shift in the distributions suggests that the timing process may not be completely proportional.

Like keypeck or barpress time-out responding for stimulus change, location in the rear of the chamber was generally an increasing function of interval value. This conclusion is limited to 4 subjects since the results were less consistent for the other 2 . The reason for this latter finding is unclear, but it suggests that time in the rear may include activities not directly related to consequent stimulus change. Perhaps the locational operant used was more sensitive to transient topographic variations (Ferster \& Skinner, 1957) in behavior than a keypeck or barpress 
FIXED TIME
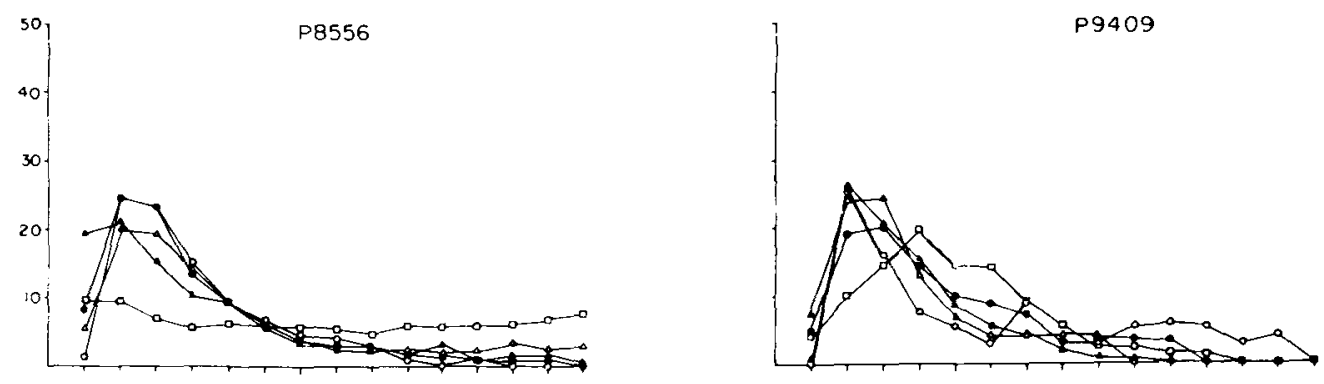

FIXED INTERVAL
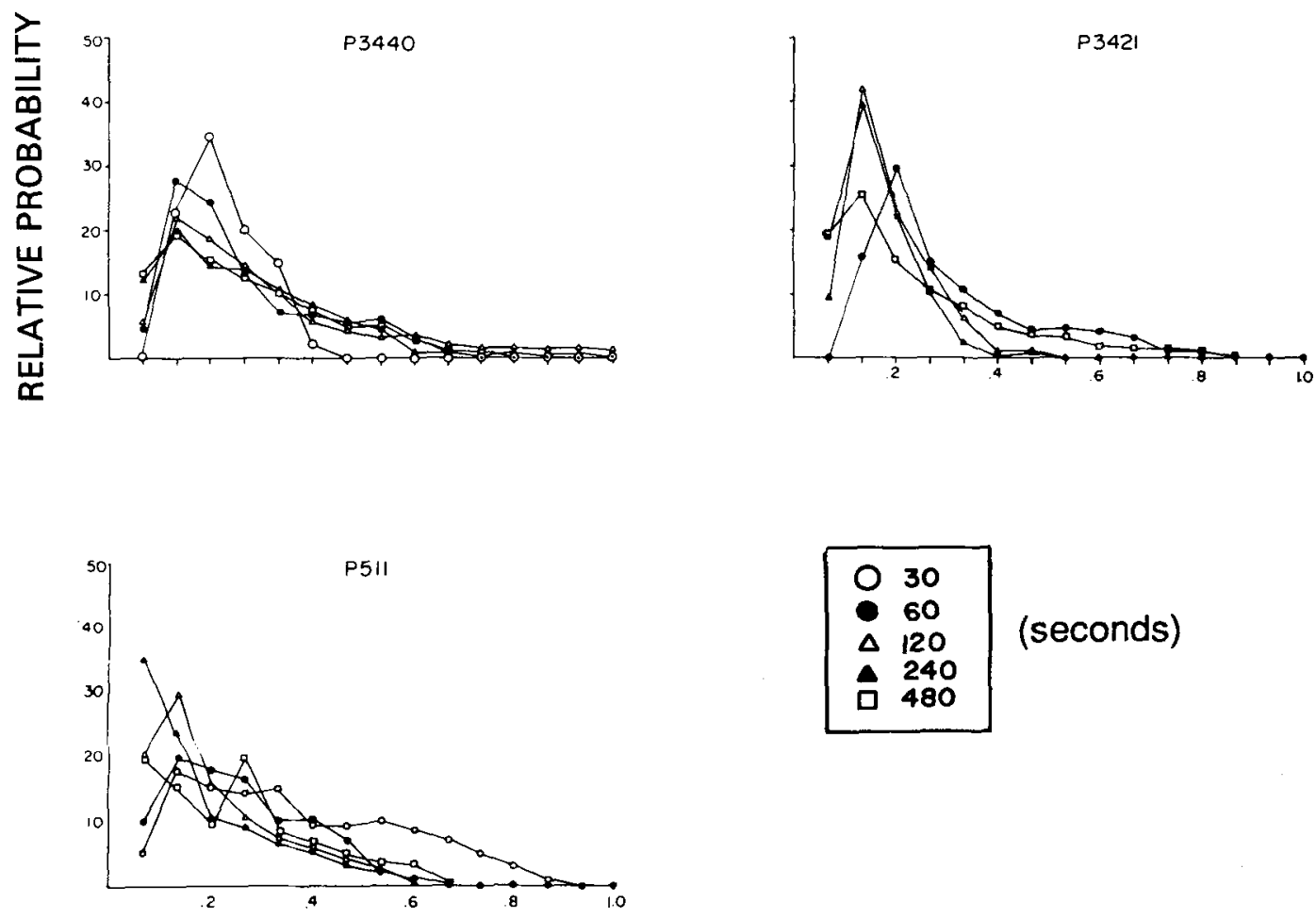

(seconds)

\section{PROPORTION OF INTERVAL}

Figure 5. Relative probability of location in the rear as a function of time between reward deliveries for the ascending series with contingent stimulus change.

operant would have been. On the other hand, previous reports on the relation between time-out responding and interreinforcer interval are somewhat ambiguous. Some experimenters have found a bitonic relation (Brown \& Flory, 1972), whereas others have found an increasing function (Azrin, 1961; Lydersen et al., 1980). However, another study found no relation at all (Zimmerman \& Ferster, 1964).

\section{EXPERIMENT 2}

Unlike traditional time-out studies, Experiment 1 used a locational operant (spatial retreat) to produce stimulus change rather than an explicitly defined operant. The purpose of Experiment 2 was to further explore the hypothesis that spatial retreat is a general form of time-out responding by directly comparing spatial retreat with key- 
peck responding for stimulus change. In this experiment, subjects from Experiment 1 were exposed to several interreinforcer intervals during which they were given the opportunity to keypeck to produce a stimulus change identical to that produced by interrupting the rear photobeam in Experiment 1. The experiment had three objectives.

The first objective was to determine whether the stimulus-change condition used in Experiment 1 had the efficacy to support operant keypecking. If the degree of stimulus change used in the previous experiment does not reinforce operant keypecking as reported in many previous experiments (e.g., Brown \& Flory, 1972; Lydersen et al., 1980), then the generality of the findings in Experiment 1 will be in doubt.

The second objective was to examine, with the same subjects used in Experiment 1, the proportion of total session time spent in time-out as a function of the interval between reward presentations. A comparison of these functions with those obtained in Experiment 1, in which location in the rear produced stimulus change, will indicate whether the level of spatial retreat and operant responding for stimulus change are comparable and are similarly affected by a change in reinforcer density.

The final objective was to examine the allocation of time spent under stimulus change within each interval. Will the distribution of time spent in stimulus change be the same as in Experiment 1? Will changing the interval between reward deliveries have the same effect upon the distributions of time spent in stimulus change as it did previously? An affirmative answer to these questions will further strengthen the link between operant time-out responding and spatial retreat.

\section{Method}

Subjects. The subjects were the same pigeons used in Experiment 1 . They were maintained under identical conditions.

Apparatus. The apparatus was the same one that was used in Experiment 1 with one addition. A second response key was mounted 2.5 in. to the left of the response key centered above the grain aperture. This key was illuminated with white light during all experimental sessions except the first five. Time spent in timeout was cumulated in 15 equal time bins that varied from 2 to $32 \mathrm{sec}$ depending on the interval schedule in effect. For both FI and FT groups, pecks to the time-out key were accompanied by an audible click.

Procedure. All subjects were exposed to four interreinforcer intervals in the following order: $120,30,480$, and $120 \mathrm{sec}$. As in Experiment 1, Subjects P9409 and P8556 were exposed to fixedtime schedules and Subjects P511, P6933, P3440, and P3421 to fixed-interval schedules. To obtain baseline measurements, the subjects were initially exposed to five sessions at the 120 -sec interval with the time-out key unlighted and stimulus change unavailable. In all subsequent sessions, the subjects both initiated and terminated a change in stimulus conditions identical to that in Experiment 1 by pecking the white response key. The first peck to the white response key initiated a time-out that remained in effect until a second peck occurred. During the time-out condition, the time-out response key remained illuminated with white light. To ensure that reward would not be delivered while the time-out was in effect, a protective contingency was instituted that prevented grain presentation for 5, 10, and $15 \mathrm{sec}$ after reinstatement of stimuli associated with reward at the 30,120 , and $480-\sec$ intervals, respectively.

\section{Results and Discussion}

All subjects initiated stimulus change by pecking the white response key during Session 6, when it first became available, and continued to do so for the remainder of the experiment. Figure 6 presents the percentage of the session spent in keypeck-initiated time-out for each subject at each interval value. The filled circles represent the first exposure to each interval value, and the unfilled circle depicts the second exposure to the 120 -sec interval value. For comparison, the percentage of the session spent in time-out when it was initiated by location in the rear on the ascending series in Experiment 1 is included (filled triangles). As can be seen in Figure 6, the stimulus change not only supported keypecking, but for 4 of 6 subjects (P9409, P511, P6933, and P3440), the proportion of the session spent in keypeck-initiated time-out was generally comparable to that for stimulus change produced by photobeam interruption. Relative to other subjects in Experiment 2, P6933 spent little time in the stimulus-change condition, which was also true for this subject in Experiment 1 , in which stimulus change was consequent upon location in the rear. Unlike the other 4 subjects, P3421 and P9409 spent somewhat more time in time-out when it was produced by keypeck than when it was produced by location in the rear.

In addition to exhibiting comparable levels of time spent in time-out, the percentage of the session spent in timeout as a function of the interreinforcer interval was similar (with the exception of P3421) if it was produced by

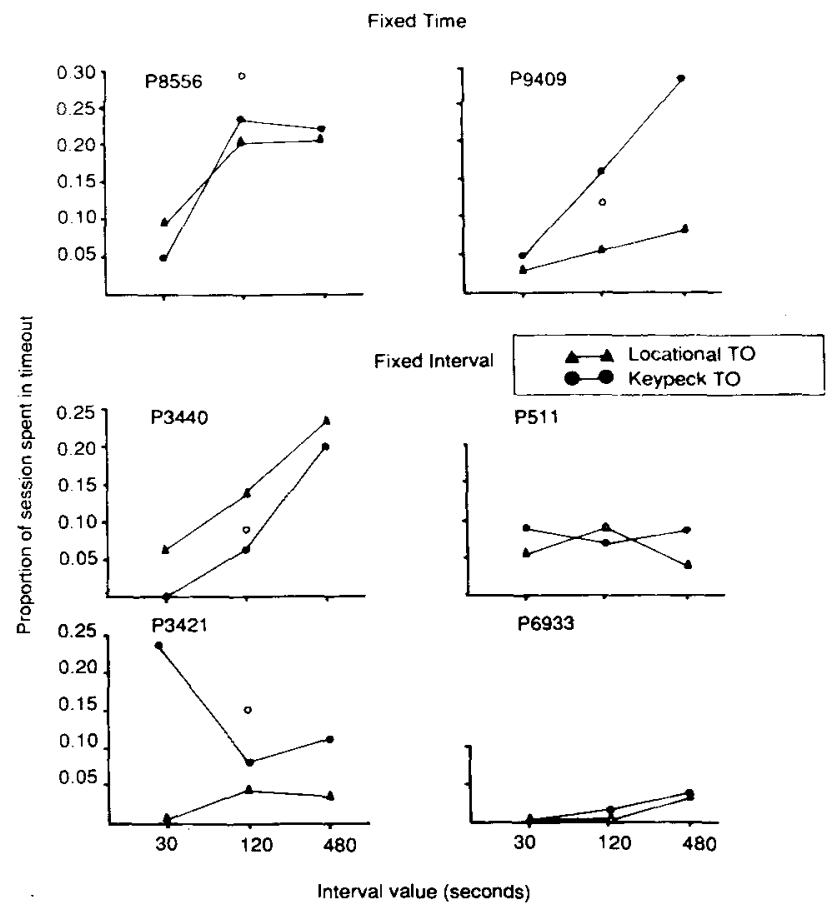

Figure 6. Relative probability of a keypeck-initiated stimulus change as a function of interreinforcer value. For comparison, the probability of time in the rear when accompanied by contingent stimulus change is also plotted. The open circle represents the second exposure to the 120-sec interval value for Experiment 2. 
keypecking or by location. For 4 subjects (P6933, P3440, P9409, and P8556), the proportion of session time spent in time-out was generally an increasing function of the interval between reinforcer deliveries.

Figure 7 shows the allocation of the time spent in keypeck-produced time-out within the interreinforcer interval. These functions are normalized (Gibbon, 1977) and comparable to those shown in Figures 4 and 5 in Experiment 1 . The functions for the $30-\mathrm{sec}$ interval are omitted, as are those of P6933, because the amount of time spent in time-out was so low as to preclude characterization in this manner. As can be seen in Figure 7, probability that a time-out was in effect increased after grain presentation, reached a peak $15 \%-25 \%$ through the interval, and decreased thereafter. The temporal allocations of time spent in stimulus change are very similar, regardless of whether stimulus change was produced and terminated by a single operant keypeck or by locational operants in Experiment 1.

Although only two interreinforcer intervals can be compared, the probability functions in Figure 7 appear to possess the same proportional timing attributes as those obtained with a locational operant in Experiment 1 . The functions for two very different interval values superimpose on one another quite well. This indicates that time spent in time-out was allocated with respect to the proportion of the interval that had elapsed rather than to the $a b-$ solute time since grain delivery. The within-subject comparison of time-out functions for locational and keypeck responses further strengthens the assertion that they are
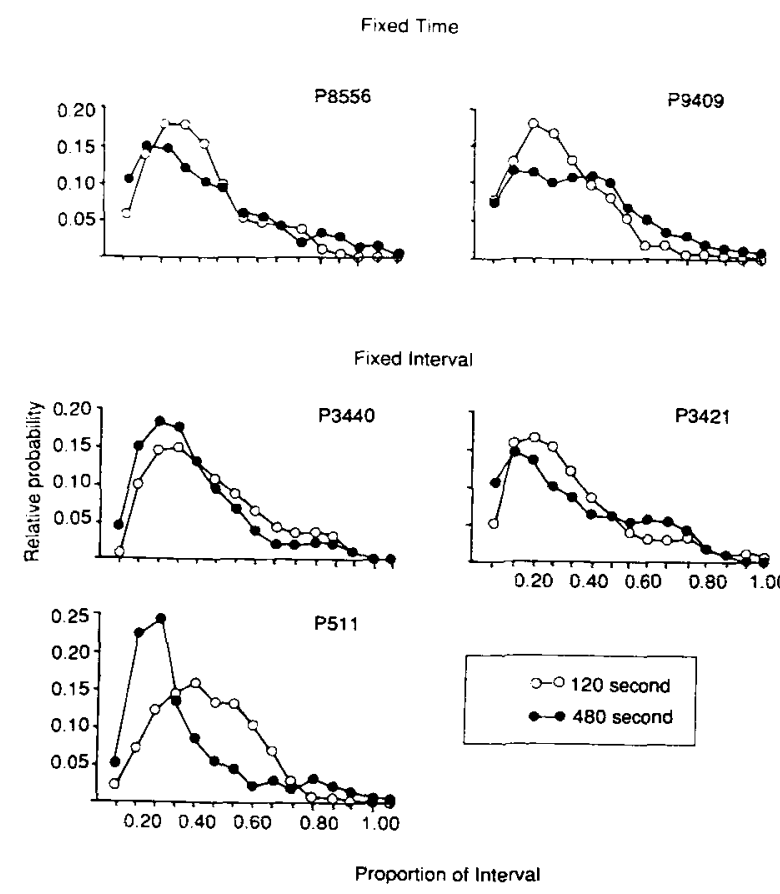

Figure 7. Relative probability of a keypeck-initiated stimulus change as a function of time in the interval between reward presentations. a common behavioral class. The similarity even applies to individual subject differences in degree of proportional timing; for example, the functions for P511 provide a poor example of proportional timing, with both a locational (Experiment 1) and a keypeck (Experiment 2) time-out response.

\section{GENERAL DISCUSSION}

The results of Experiment 2, in conjunction with those obtained in Experiment 1 and in the preliminary study, underscore the similarities between spatial retreat and keypecking for stimulus change. The results suggest that even when an experimentally arranged means of changing stimuli associated with intermittent reward is not provided, subjects position themselves in a way that removes or changes stimuli associated with intermittent reward (Rand, 1977; Wasserman et al., 1974). This may involve, in part, turning or moving away from the reinforcer dispenser. If an experimentally arranged means of changing stimuli is provided, subjects will produce stimulus change at times when they normally would be away from the reinforcer dispenser.

The similar properties of spatial withdrawal and keypecking for stimulus change suggest that those behaviors are members of a class of postreinforcement ambulatory and exploratory activities that have been observed during intermittent reinforcement schedules (Killeen, 1975; Muller \& Cheney, 1975) and that serve to change stimuli associated with periodic reward (Brown \& Flory, 1972). At least three aspects of the experiments are consistent with this hypothesis.

First, we found that movement away from the reinforcer dispenser, whether or not accompanied by contingent stimulus change, and keypecking for stimulus change tend to occur soon, although not always immediately, after reward delivery. Our data are consistent with those previously obtained using keypeck and barpress operants in pigeons and rats, respectively (Brown \& Flory, 1972; Lydersen et al., 1980). The data are also consistent with the distributions of general locomotor behavior of pigeons during periodic reward schedules obtained by Killeen (1975).

Second, the level of both keypeck time-out and spatial withdrawal, whether accompanied or unaccompanied by contingent stimulus change, are similarly affected by changes in interreinforcer interval. These functions are generally comparable with those obtained in previous time-out experiments (Brown \& Flory, 1972; Lydersen et al., 1980). In this respect, however, these data are not consistent with Killeen's (1975) general activity data. Killeen found that the level of activity is an inverse function of the interreinforcer interval value, whereas we found that the proportion of time spent in time-out is an increasing function of the interval value. The reason for the difference is unclear, but it suggests that general activity level does not reflect the tendency to seek stimulus change. Thus, at longer interval values, overall activity 
may be lower, but subjects may actually be spending more time away from the reinforcer dispenser, producing a high degree of stimulus change.

Finally, we found that both keypeck time-out and spatial withdrawal are distributed with respect to proportional rather than absolute time between reward presentations. Rather than following a fixed time course, the probability of both behaviors is sensitive to the time that has elapsed since reward delivery relative to the total interval between reinforcers. These data are consistent with mathematical formulations of the temporal structure of interim behavior and general activity presented by Gibbon (1977) and Killeen (1975). In light of subsequent work in our laboratory (Campagnoni et al., 1986), this result also suggests a fundamental temporal difference between time-out activities, including spatial withdrawal, and other interim behaviors such as schedule-induced attack and polydipsia (cf. Falk, 1977; Staddon, 1977; Staddon \& Simmelhag, 1971). Attack (Campagnoni et al., 1986) and polydipsia (Lawler \& Cohen, 1985) occur earlier in the interval and have a fixed onset and temporal pattern regardless of the interval between reward deliveries. Cohen, Looney, Campagnoni, and Lawler (1985) suggested that this difference is a basis for distinguishing between two functionally and topographically distinct types of interim behaviors.

In a broader context, the results of this study indicate that the classic free-operant performance that emerges during exposure to intermittent reinforcement includes the interaction of two opposing motivational tendencies that are reflected in two types of operants: those that serve to assimilate and preserve the positive reward, and others, maintained by stimulus change, that serve to accommodate the unavailability of reward. For some researchers (e.g., Falk, 1977; Wasserman et al., 1974), this latter tendency is thought of as a reaction to the aversiveness of the dispenser area when a reinforcer is unlikely to occur. In applying this idea to the possible origin of adjunctive behaviors, Falk (1977) suggested that such behaviors stem from a conflict between the opposing behavioral vectors to approach and escape from intermittently available reinforcement. As evidence for the escape vector, Falk pointed to the time-out literature and postulated that keypecking for stimulus change (time-out) is functionally similar to, but perhaps not equivalent to, spatial retreat. Although the present results do not lend support to the aversiveness notion as discussed below, they do suggest that keypeck for stimulus change and spatial retreat are functionally homologous.

The idea that subjects are trying to change aversive stimuli signaling nonreward in the postreinforcement period is not universally accepted. Some investigators have suggested that time-out and spatial retreat are maintained by the consequent presentation of novel stimuli and not by the termination of aversive ones (Appel, 1963; Innis \& Honig, 1979; Zimmerman \& Ferster, 1964). From this perspective, Cohen et al. (1985) suggested that spatial retreat and keypeck time-out serve equivalent exploratory functions. The fact that spatial retreat and keypeck timeout in the present study, as well as in previous ones (e.g., Innis \& Honig, 1979), do not begin immediately after reinforcer termination is consistent with this alternative view. If responding for stimulus change was an attempt to escape stimuli signaling nonreward, it should be strongest immediately following reward termination.

In conclusion, the results of these experiments suggest that the tendency to change stimuli associated with intermittent reward during the postreinforcer period is an intrinsic behavioral aspect of periodic reward and occurs even when there is not an experimentally arranged contingency available to the subject. Under natural conditions, such intrinsic activities may serve the open-ended function of keeping the subject apprised of alternative cues and sources of reinforcement.

\section{REFERENCES}

APPEL, J. B. (1963). Aversive aspects of a schedule of positive reward. Journal of the Experimental Analysis of Behavior, 6, 423-427.

ATOR, N. A. (1980). Mirror pecking and timeout under a multiple fixedratio schedule of food delivery. Journal of the Experimental Analysis of Behavior, 34, 319-338.

AzrIN, N. H. (1961). Time-out from positive reinforcement. Science, $133,382-383$.

Brown, T. G., * Flory, R. K. (1972). Schedule-induced escape from fixed-interval reinforcement. Journal of the Experimental Analysis of Behavior, 17, 395-403.

Campagnoni, F. R., Lawler, C. P., Cohen, P. S. (1986). Temporal patterns of reinforcer-induced general activity and attack in pigeons. Physiology \& Behavior, 37, 577-582.

Cohen, P. S., LoOney, T. A., Campagnoni, F. R., \& Lawler, C. P. (1985). A two-state model of reinforcer induced motivation. In F. R. Brush \& J. B. Overmier (Eds.), Affect, conditioning and cognition: Essays on the determinants of behavior. Hillsdale, NJ: Erlbaum.

Dews, P. B. (1970). The theory of fixed-interval responding. In W. N. Schoenfeld (Ed.), The theory of reinforcement schedules. New York: Appleton-Century-Crofts.

FALK, J. L. (1977). The origin and functions of adjunctive behavior. Animal Learning \& Behavior, 5, 325-335.

FALK, J. L. (1981). The environmental generation of excessive behavior. In S. J. Mule (Ed.), Behavior in excess (pp. 313-337). New York: Free Press.

FERSTER, C. B., \& SKINNER, B. F. (1957). Schedules of reinforcement. New York: Appleton-Century-Crofts.

GibBoN, J. (1977). Scalar expectancy theory and Weber's law in animal timing. Psychological Review, 84, 279-325.

Herrnstein, R. J. (1961). Relative and absolute strength of response as a function of frequency of reinforcement. Joumal of the Experimental Analysis of Behavior, 4, 267-272.

INNIS, N. K., HoNiG, W. K. (1979). Stimulus control of behavior during the postreinforcement pause of FI schedules. Animal Learning \& Behavior, 7, 203-210.

Killeen, P. (1975). On the temporal control of behavior. Psychological Review, 82, 89-115.

KILlEEN, P. (1979). Arousal: Its genesis, modulation and extinction. In M. D. Zeiler \& P. D. Harzem (Eds.), Advances in the analysis of behavior: Vol. 1. Reinforcement and the organization of behavior. Chichester, England: Wiley.

LAWler, C. P., \& CoHen, P. S. (1985, March). Temporal patterns of schedule-induced licking in rats exposed to periodic reward. Paper presented at the meeting of the Eastern Psychological Association, Boston, MA.

Lydersen, T., Perkins, D., Thome, S., \&owman, E. (1980). Choice of timeout during response-independent food schedules. Journal of the Experimental Analysis of Behavior, 33, 59-76. 
MCFARLAND, D. J. (1969). Mechanisms of behavioral disinhibition. Animal Behaviour, 17, 238-242.

Muller, P. G., \& Cheney, C. D. (1975, November). Varying the temporal location of the opportunity to attack within the interfood-interval. Presented at the meeting of the Psychonomic Society, Denver, CO.

RAND, J. F. (1977). Behaviors observed during S- in a simple discrimination leaming task. Joumal of the Experimental Analysis of Behavior, 27, 103-117.

Staddon, J. E. R. (1977). Schedule-induced behavior. In W. K. Honig \& J. E. R. Staddon (Eds.), Handbook of operant behavior (pp. 125-152). Englewood Cliffs, NJ: Prentice-Hall.

Staddon, J. E. R., \&immelhag, V. L. (1971). The "superstition" experiment: A reexamination of its implications for the principles of adaptive behavior. Psychological Review, 78, 3-43.
Wasserman, A. W., Franklin, S. R., Hearst, E. (1974). Pavlovian appetitive contingencies and approach versus withdrawal to conditioned stimuli in pigeons. Journal of Comparative \& Physiological Psychology, 86, 616-627.

Yoburn, B. C., Cohen, P. S., Campagnoni, F. R. (1981). The role of intermittent food in the induction of attack in pigeons. Journal of the Experimental Analysis of Behavior, 36, 101-117.

Zimmerman, J., \& Ferster, C. B. (1964). Some notes on time-out from reinforcement. Journal of the Experimental Analysis of Behavior, 7, 13-19.

(Manuscript received February 22, 1988; revision accepted for publication July 25,1988 .) 